CASE REPORT

\title{
Prilokain Kullanımı Sonrası Gelişen Edinsel Methemoglobinemi
}

\section{Acquired Methemoglobinemia After Application of Prilocaine}

\author{
Çapan Konca, Zelal Kahramaner*, Mehmet Çoban*, Yeliz Mahanoğlu*, Mehmet Tekin*, Mehmet Turgut* \\ Adıyaman Üniversitesi Tıp Fakültesi, Çocuk Sağlığı ve Hastalıkları Anabilim Dalı, Çocuk Yoğun Bakım Ünitesi, Adıyaman, Türkiye \\ Adıyaman Üniversitesi Tıp Fakültesi, Çocuk Sağlığı ve Hastalıkları Anabilim Dalı, Adıyaman, Türkiye
}

\section{Anahtar kelimeler \\ Çocukluk çağı, methemoglobinemi, prilokain kullanımı}

\section{Key words}

Childhood, methemoglobinemia, application of prilocain

Geliş Tarihi/Received : 29.04.2013

Kabul Tarihi/Accepted : 22.07.2013

DOI: $10.4274 /$ jcp. 84803

Yazışma Adresi/Address for Correspondence: Dr. Çapan Konca, Adıyaman Üniversitesi Tıp Fakültesi, Çocuk Sağlığı ve Hastalıkları Anabilim Dalı, Çocuk Yoğun Bakım Ünitesi, Adıyaman, Türkiye

Gsm: +90 5054896904

E-posta: dr.capan@hotmail.com

(c) Güncel Pediatri Dergisi, Galenos Yayınevi tarafından basılmıştır (c) The Journal of Current Pediatrics, published by Galenos Publishing.

\section{Özet}

Prilokain, pek çok alanda kullanılan lokal anestetik bir ajandır, ancak hayatı tehdit edebilen bir yan etki olan methemoglobinemiye neden olabilmektedir. Methemoglobinin $\mathrm{O}_{2}$ taşıma kapasitesi düşüktür ve doku düzeyinde hipoksiye neden olabilir. Sünnet operasyonundan iki saat sonra ağız bölgesinde, ellerinde ve ayak parmaklarında morarma yakınması ile acil servise başvuran 54 günlük bebeğin fizik muayenesinde mevcut durumu açıklayacak patoloji saptanmadı. Oksijen tedavisine yanıtsız olan hasta yoğun bakım ünitesine alındı. Sünnet işlemi öncesi $2 \mathrm{mg} / \mathrm{kg}$ prilokain yapıldığı öğrenilen, oksijen tedavisine rağmen satürasyon değerleri düşük seyreden ve kan gazı incelemesinde methemoglobin düzeyi $\% 24,7$ saptanan hastaya methemoglobinemi tanısı konuldu. Hastaya $300 \mathrm{mg} / \mathrm{kg} / \mathrm{doz}$ askorbik asit başlandı ve 24 saatlik izlem sonrası şifa ile taburcu edildi. Cerrahi girişim sonrasında siyanoz gelişen ve $\mathrm{SaO}_{2}$ ile $\mathrm{pO}_{2}$ değerleri arasında uyumsuzluk saptanan hastalarda methemoglobinemi düșünülmeli ve gelişebilecek problemler açısından tam donanımlı çocuk yoğun bakım ünitelerinde izlenmelidirler. (Güncel Pediatri 2014;1:54-7)

\begin{abstract}
Prilocaine is a local anesthetic agent and is widely used in most of ambulatory procedures, but it can cause methemoglobinemia which is a life-threatening condition. Methemoglobinemia may cause hypoxia of tissue because methemoglobin has less oxygen carrying capability than hemoglobin. A 54-dayold boy who developed cyanosis around his mouth, on his hands and toes two hours after the circumcision operation was admitted to the emergency department. No abnormality was established on his physical examination except for cyanosis. Cyanosis did not improve with oxygen administration and the patient was admitted to intensive care unit. His history revealed that prilocaine hydrochloride $(2 \mathrm{mg} /$ $\mathrm{kg}$ ) was administered subcutaneously as local anesthesia prior to circumcision operation. Diagnosis of methemoglobinemia was established in the patient in whom saturation levels were low in spite of the oxygen therapy and in whom methemoglobinemia level was $24.7 \%$. His cyanosis completely disappeared after administration of intravenous ascorbic acid $(300 \mathrm{mg} / \mathrm{kg} / \mathrm{dose})$ and he was discharged after a 24-hour follow-up period with recovery. Methemoglobinemia should be considered in cases with cyanosis and inconsistency between oxygen saturation and partial arterial oxygen pressure. These cases should be monitored in pediatric intensive care units for lethal complications. (The Journal of Current Pediatrics 2014;1:54-7)
\end{abstract}




\section{Giriş}

Normal koşullarda hemoglobinde bulunan demir iki değerlidir $\left(\mathrm{Fe}^{++}\right)$. Hemoglobindeki demirin okside olup, üç değerli $\left(\mathrm{Fe}^{+++}\right)$duruma geçmesiyle methemoglobinemi oluşur (1). Methemoglobin, $\mathrm{O}_{2}$ taşıyamaz ve hemoglobin-oksijen dissosiasyon eğrisini sola kaydırarak dokulara daha zor $\mathrm{O}_{2}$ verilmesine yol açar. Fizyolojik şartlarda methemoglobin total Hb'nin \%1'i kadardır ve \%2-\%3'ünü geçmez. Sağlıklı bireylerde de bazen bir takım oksidan maddelerle temas sonrası methemoglobin oluşabilmektedir, ancak alyuvarlarda bulunan sitokrom b5 redüktaz enzim sistemi sayesinde methemoglobin düzeyleri düşük tutulabilmektedir (2). Hafif olgular asemptomatik olabilmekle birlikte; ciddi olgularda siyanoz, takipne, taşikardi, hipotansiyon, konfüzyon ve hatta ölüm görülebilir. Methemoglobinemi olgularında kan methemoglobin düzeyleri ile ilişkili değișen derecede siyanoz saptanabilmektedir. Methemoglobin düzeyi $\% 10$ 'u aşınca periferik siyanoz saptanmaya başlar, $\% 35$ ve üzeri değerlerde doku hipoksisi ile birlikte yaygın siyanoz görülür iken; düzey \%70'e ulaştığında koma ortaya çıkar ve bu durum tedavi edilmediğinde ölümle sonuçlanabilir $(2,3)$.

$\mathrm{Bu}$ çalışmada, sünnet sırasında analjezik amaçlı prilokain ile dorsal penil sinir bloğu (DPSB) uygulanan, akut methemoglobinemi gelişen ve iki saat sonra morarma yakınması ile çocuk yoğun bakım ünitemize sevk edilen 54 günlük bir erkek hasta sunulmuştur.

\section{Olgu Sunumu}

Sünnet yapıldıktan iki saat sonra ağız bölgesinde, ellerinde ve ayak parmaklarında morarma yakınması ile acil servise getirilen 54 günlük bebeğin ilk muayenesinde genel durumunun kötü olduğu, huzursuzluğunun ve siyanozunun olduğu görülmüş, ancak yapılan fizik muayenede mevcut durumu açıklayabilecek kardiyak veya solunumsal bir patoloji saptanmamıştı. Maske ile oksijen uygulanmasına (8 L/dk) rağmen siyanozunda düzelme olmayan hasta konsülte edildi ve çocuk yoğun bakım ünitesine transferi sağlandı. Çocuk yoğun bakım ünitesine alındığında yapılan ilk değerlendirmede huzursuzluk, peroral ve periferik siyanoz dişında patolojik bulgu saptanmadi. Hastaya maske ile oksijen verilmeye devam edildi (10 L/dk) ancak pulse oksimetre ile ölçülen oksijen satürasyonu \%85'in üstüne çıkmadı. İlk bakılan kapiller kan gazında $\mathrm{pH}: 7,39, \mathrm{pCO}_{2}: 34,2$ $\mathrm{mmHg}, \mathrm{pO}_{2}: 76,4 \mathrm{mmHg}, \mathrm{HCO}_{3}: 21,4 \mathrm{mEq} / \mathrm{l}$ ve methemoglobin: \%24,7 saptandi. Operasyonu gerçekleştiren hekim ile görüşüldüğünde DPSB uygulaması için preoperatif olarak $2 \mathrm{mg} / \mathrm{kg}$ prilokain (Citanest \%5) yapıldığı öğrenildi. Mevcut bulgularla hastaya akut methemoglobinemi tanıs1 konuldu. Çekilen elektrokardiyografi (EKG) sinüzal taşikardi dişında normaldi. Arka-ön akciğer grafisi ve telekardiyografisi normal olarak değerlendirildi. Rutin laboratuar incelemelerinde biyokimyasal veya hematolojik patoloji saptanmad. Kalitatif olarak glukoz-6-fosfat-dehidrogenaz (G6PD) enzim eksikliği saptanmadı. Hastaya $10 \mathrm{lt} / \mathrm{dk}$ maske ile oksijen, $300 \mathrm{mg} / \mathrm{kg} / \mathrm{doz}$ askorbik asit ve $\% 5$ dekstroz içeren mayi tedavisi başlandı. Hasta monitörize edildi, yakın vital bulgu takibi ve 4 saat arayla kan gazı izlemine alındı (Tablo 1). Tedavinin ikinci saatinde peroral bölgede, sekizinci saatinde ise tüm vücutta siyanoz kayboldu ve oksijen tedavisi kesildi. On altıncı saatinde ise methemoglobin düzeyleri $\% 2$ 'nin altına düşen hasta 24 saatlik yatış sonrası şifa ile taburcu edildi.

Tablo 1. Hastanın kapiller kan gazı ölçüm sonuçları

\begin{tabular}{lllll}
\hline $\begin{array}{l}\text { Yatış Süresi } \\
\text { (saat) }\end{array}$ & $\begin{array}{l}\mathrm{pCO}_{2} \\
(\mathrm{mmHg})\end{array}$ & $\begin{array}{l}\mathrm{pO}_{2} \\
(\mathrm{mmHg})\end{array}$ & $\begin{array}{l}\text { Oksijen satürasyonu } \\
(\%)\end{array}$ & $\begin{array}{l}\text { Methemoglobin düzeyi } \\
(\%)\end{array}$ \\
\hline 0 & 34,2 & 76,4 & 85 & 24,7 \\
4 & 33,8 & 80,2 & 94 & 14,7 \\
8 & 37,6 & 76,3 & 99 & 7,4 \\
12 & 37,4 & 78,7 & 98 & 2,8 \\
16 & 35,2 & 84,7 & 99 & 1,9 \\
20 & 34,3 & 83,1 & 100 & 1,7 \\
24 & 37,7 & 79,2 & 99 & 1,2 \\
\hline
\end{tabular}




\section{Tartışma}

Siyanoz ile başvuran dolaşım ve solunum sistem bulguları normal olan hastada methemoglobinemi ayırıcı tanılar arasında düşünülmelidir. Yaşamın ilk aylarında sitokrom b5 redüktaz enzim aktivitesinin geçici olarak eksik olması da yenidoğan ve süt çocuklarının methemoglobinemiye daha yatkın olmalarına yol açmaktadır (4). Klinik pratikte methemoglobinemi konjenital veya akkiz olarak görülebilir. Akkiz methemoglobineminin en sik nedenleri sülfonamidler, lokal anestezik ilaçlar ve nitrat içeren sebzelerdir (5). Lokal anestezik ilaçlardan prilokain klinikte yaygın kullanım alanına sahiptir ve kolaylıkla methemoglobinemiye neden olur (6).

Methemoglobinemide klinik bulgular kan methemoglobin düzeylerine bağımlı olarak değişkenlik gösterir. Siyanoz, methemoglobin seviyesi $1,5 \mathrm{~g} / \mathrm{dl}$ veya toplam hemoglobinin \%8-\%12'sini aştığında belirgin hale gelir ve oksijen desteğine rağmen iyileşme görülmez. Methemoglobin yüzdesi \%30-\%50 arasında olduğunda yorgunluk, konfüzyon, takipne ve taşikardi, $\% 50$ 'nin üzerinde koma, konvülziyon, aritmi ve asidoz olur ve \%70'in üzerindeki konsantrasyonlar ise ölümle sonuçlanabilir (7-9). Hastamızda başvuru anında methemoglobin düzeyi \%24,7 idi ve klinik bulgu olarak huzursuzluk, peroral siyanoz, periferik siyanoz, taşipne ve taşikardi mevcut idi. Tedavinin ikinci saatinde tüm klinik bulgular normale geldi. Literatürde taşipne ve taşikardi için methemoglobin düzeyinin biraz daha yüksek olması gerektiği bildirilmiş olmasına rağmen; hastamızdaki bu durum methemoglobin düzeyi ile ilişkili olabileceği gibi hastamızın huzursuzluğu ve ajitasyonu ile ilgili de oluşmuş olabilir.

Kimyasal maddelere bağlı toksik methemoglobinemide, öncelikliolarak, uygulamaya son verilmesi ve mümkünse maddenin vücuttan uzaklaştırılması gereklidir. Methemoglobin düzeyi \%20'den düşükse genelde neden olan ilacın kesilmesiyle düzelme görülür, ancak yenidoğan ve erken süt çocukluğu döneminde tedavi gerekebilir $(1,10)$. Daha yüksek konsantrasyonlarda ise metilen mavisi, $1-2 \mathrm{mg} / \mathrm{kg}$ dozunda, en az beş dakika süreyle intravenöz olarak kullanılabilir ve gerekirse bir saat sonra doz tekrarlanabilir. Metilen mavisi, kofaktör olarak nikotinamid adenin dinükleotit fosfatın (NADP) indirgenmiş hali olan NADPH kullanan ve sitokrom b5 redüktaz enziminden ayrı olan bir başka redüktaz sistemini kullanarak methemoglobin düzeyini düşürür. NADPH için normal heksoz monofosfat şantı gerektiğinden, G6PD eksikliğinde metilen mavisi kullanılmamalıdır. Bu durumda metilen mavisi yerine askorbik asit kullanılabilir $(2,6,11)$. Prilokaine bağlı toksik methemoglobinemi gelişen ve intravenöz askorbik asit tedavisi uygulanan iki hastanın değerlendirildiği bir çalışmada, toksik methemoglobinemi vakalarında metilen mavisi bulunamadığında veya G6PD eksikliği şüphesi varsa, intravenöz askorbik asit kullanımının etkin olduğu bildirilmiştir (12). İzlemde klinik yanıtla eş zamanlı olarak saatler içinde methemoglobin seviyesinin de düşmesi beklenir. Kantitatif Glukoz6-fosfat-dehidrogenaz (G6PD) enzim düzeyi ölçme ve intravenöz metilen mavisi solüsyonu elde etme imkanımız olmadığı için hastamıza tek doz 300 $\mathrm{mg} / \mathrm{kg}$ askorbik asit verildi ve tedavinin 8 . saatinde klinik, 24. saatinde ise laboratuvar bulgularında tam düzelme sağlandı.

Prilokain özellikle çocuklarda tedavi dozlarında dahi methemoglobinemiye neden olabilen bir ajandır. Literatürde altı aydan küçük bebeklerde $2 \mathrm{mg} / \mathrm{kg}$ 'dan verilen prilokainin methemoglobinemiye neden olduğu bildirilmiş ve bu hastalarda prilokain kullanımı önerilmemektedir (13). Küçük çocuklarda özellikle ilk üç aylık dönemde bupivakainin daha güvenilir bir lokal anestezik olduğu birçok çalışmada bildirilmiştir (1416). Hastamızda $2 \mathrm{mg} / \mathrm{kg}$ prilokain uygulanmasından iki saat sonra methemoglobinemi bulguları görülmeye başlanmıştı.

\section{Sonuç}

Küçük cerrahi girişim sonrasında siyanoz gelişen ve $\mathrm{SaO}_{2}$ ile $\mathrm{pO}_{2}$ değerleri arasında uyumsuzluk saptanan hastalarda methemoglobinemi düşünülmeli ve ilaç kullanımı sorgulanmalıdır. $\mathrm{Bu}$ hastalar, methemoglobineminin ağırlaşması, hipoksemi ve gelişebilecek ek problemler açısından tam donanımlı çocuk yoğun bakım ünitelerinde izlenmelidirler. Çocuk hastalarda lokal anestezik madde kullanımında dikkatli olunmalıdir.

\section{Kaynaklar}

1. Honig GR. Hemoglobin disorder. In: Behrman RE, Kleigman RM, Jenson HB (eds). Nelson Textbook of Pediatrics. Philadelpiha: Saunders, 2000:1478-88. 
2. Svecová D, Böhmer D. Congenital and acquired methemoglobinemia and its therapy. Cas Lek Cesk 1998;137:168-70.

3. Benini D, Vivo L, Fanos V. [Acquired methemoglobinemia: a case report]. Pediatr Med Chir 1998;20:411-3.

4. Sivasli E, Gursoy T, Yurdakok M. Which local anesthesia should be used in neonatal circumcision in newborns? Saudi Med J 2005;26:690-1.

5. Liao YP, Hung DZ, Yang DY. Hemolytic anemia after methylene blue therapy for aniline-induced methemoglobinemia. Vet Hum Toxicol 2002;44:19-21.

6. Kara A, Yiğit S, Aygün C, Oran O. Toxic methemoglobinemia after injection of prilocaine in a newborn. A case report. Turk J Pediatr 1998;40:589-92.

7. Bristol I, Brown J, Slomovitz BM, Shannon VR, Eifel PJ. Methemoglobinemia induced by topical vaginal sulfanilamide cream in a patient with cervical cancer: a case report. Gynecol Oncol 2005;97:953-6.

8. Armstrong C, Burak KW, Beck PL. Benzocaine-induced methemoglobinemia: a condition of which all endoscopists should be aware. Can J Gastroenterol 2004;18:625-9.
9. Bayard M, Farrow J, Tudiver F. Acute methemoglobinemia after endoscopy. J Am Board Fam Pract 2004;17:227-9.

10. Kumar AR, Dunn N, Naqvi M. Methemoglobinemia associated with a prilocaine-lidocaine cream. Clin Pediatr 1997;36:239-40.

11. Gülgün $\mathrm{M}$, Kul $\mathrm{M}$, Sarıcı S. Prilocaine-induced methemoglobinemia: report of two cases and review of literature. Erciyes Medical Journal 2007;29:322-5.

12. Aydoğan M, Toprak DG, Türker G ve ark. Prilokaine bağlı toksik methemaglobinemide intravenöz askorbik asit kullanımı: İki vaka takdimi. Çocuk Sağlığı ve Hastalıkları Dergisi 2005;48:65-8.

13. Guay J. Methemoglobinemia related to local anesthetics: a summary of 242 episodes. Anesth Analg 2009;108:837-45.

14. Sinisterra S, Miravet E, Alfonso I, Soliz A, Papazian O. Methemoglobinemia in an infant receiving nitric oxide after the use of eutectic mixture of local anesthetic. J Pediatr 2002;141:285-6.

15. Hahn IH, Hoffman RS, Nelson LS. EMLA-induced methemoglobinemia and systemic topical anesthetic toxicity. J Emerg Med 2004;26:85-8.

16. Gunter JB. Benefit and risks of local anesthetics in infants and children. Paediatr Drugs 2002;4:649-72. 